\title{
PITYRIASIS ROSEA - A CLINICO-EPIDEMIOLOGICAL STUDY
}

\author{
Kottaram Veetil Pavithran'1, Sreenivasan Ajayakumar², Makkuni Anoop³, Thyvalappil Anoop 4
}

${ }_{1}^{1}$ Senior Resident, Department of Dermatology, Academy of Medical Sciences, Pariyaram, Kerala, India.

${ }^{2}$ Assistant Professor, Department of Dermatology, Academy of Medical Sciences, Pariyaram, Kerala, India.

3 Professor, Department of Dermatology, Academy of Medical Sciences, Pariyaram, Kerala, India.

${ }_{4}^{4}$ Associate Professor, Department of Dermatology, Academy of Medical Sciences, Pariyaram, Kerala, India.

\section{ABSTRACT}

\section{BACKGROUND}

Pityriasis Rosea (PR) is an acute, inflammatory dermatosis of unknown cause, characterized by self-limited oval papulosquamous lesions distributed on the trunk and extremities. Seasonal incidence of PR differs widely. Clinical presentation of the disease may vary. PR may be atypical in appearance or distribution of lesions. Since there were discrepancies in various studies, it was thought worth to study the changing clinical patterns and epidemiology of Pityriasis rosea.

\section{AIM}

Of our study is to compare the clinical and epidemiological patterns of pityriasis rosea and also to determine the association of the occurrence of the disease, if any with age, sex and season.

\section{MATERIALS AND METHODS}

The study was conducted in all clinically diagnosed cases of pityriasis rosea attending the Outpatient Department of Dermatology in our institution during one-year period. Diagnosis was based on clinical grounds. The age and sex of the patient and the season was also noted. A detailed history was taken. A detailed clinical examination was made noting the morphological pattern and site of distribution of lesions. Examination of oral cavity and routine blood examination was done in all patients.

\section{RESULTS}

In our study, maximum cases between 11-30 years. Females were affected more. Most cases occurred during south west monsoon followed by pre-monsoon period. Most of the patients sought medical attentions in the first 2 to 3 weeks. Most have no associated illness. Predisposing factors in most cases are fever, drugs and atopy. Most of the cases showed moderate-to-severe itching. More patients presented with herald patch at the time of examination and was present in the decreasing frequencies over the upper limb, abdomen, back and lower limb. The duration of the secondary rash in majority of the cases within 2 weeks after the herald patch. Most of the secondary rashes are of maculopapular type and majority had involvement of trunk.

\section{CONCLUSION}

Pityriasis rosea shows a definite seasonal variation centering around the onset of south west monsoon. Young adults (11-30 yrs.) are more prone for the disease and a personal and family history of atopy has a predisposing role.

\section{KEYWORDS}

Pityriasis Rosea, Seasonal Variation, Predisposing Factors, Morphological Pattern, Age, Sex.

HOW TO CITE THIS ARTICLE: Pavithran KV, Ajayakumar S, Anoop M, et al. Pityriasis rosea - a clinico-epidemiological study. J Evolution Med. Dent. Sci. 2016;5(53):3516-3521, DOI: 10.14260/jemds/2016/811

\section{INTRODUCTION}

Pityriasis Rosea (PR) is an acute, inflammatory dermatosis of unknown cause, characterized by self-limited oval papulosquamous lesions distributed on the trunk and extremities. Clustering of cases following an index case may indirectly support an infective aetiology. In most of the reported series, females predominate over males. Studies on seasonal incidence by various authors differ widely. Reports from the temperate regions show a high incidence during cooler part of the year. Studies in tropical countries shows a high incidence in the hot dry season. Clinical presentation of the disease may vary.

Financial or Other, Competing Interest: None.

Submission 22-04-2016, Peer Review 03-06-2016,

Acceptance 09-06-2016, Published 02-07-2016.

Corresponding Author:

Dr. Sreenivasan Ajayakumar,

Department of Dermatology,

Academy of Medical Sciences,

Pariyaram-670503,

Kerala, India.

E-mail:drajayans@gmail.com

DOI: $10.14260 /$ jemds $/ 2016 / 811$
Eruption of PR follows a distinctive and remarkably constant pattern and course in $80 \%$ of cases. Prodromal symptoms are usually absent. First manifestation of the diseases is usually the appearance of herald patch followed by a generalized eruption, which characteristically follow lines of cleavage parallel to the ribs in a Christmas tree pattern. PR may be atypical in appearance or distribution of lesions. Since there were discrepancies in various studies, it was thought worth to study the changing clinical patterns and epidemiology of Pityriasis Rosea.

\section{AIMS AND OBJECTIVES}

1. To compare the clinical and epidemiological patterns of pityriasis rosea.

2. To determine the association of the occurrence of the disease, if any with age, sex and season.

\section{Inclusion Criteria}

1. All patients with clinical diagnosis of Pityriasis rosea.

2. All patients who are willing to participate in the study.

Exclusion Criteria

1. Patients who are not willing to participate in the study

2. Mentally unstable patients. 


\section{MATERIALS AND METHODS}

All clinically diagnosed cases of pityriasis rosea attending the Outpatient Department of Dermatology, at Pariyaram Medical College during June 2007 to May 2008 formed the material for this study.

Diagnosis was based on clinical grounds, i.e. morphology and distribution of the lesions, keeping in mind the atypical variants. The age and sex of the patient and the season was also noted.

A detailed history was taken with particular reference to the duration of signs and symptoms, presence of pruritus, history of prodromal symptoms, drug intake and any other predisposing factors.

A detailed clinical examination was made noting the morphological pattern and site of distribution of lesions. Examination of oral cavity was done in all patients. Routine blood examination was done in all patients.

\section{OBSERVATIONS AND RESULTS}

During the one-year period of study from June 2007 to May 2008, 55 cases of Pityriasis rosea attended in Dermatology Outpatient Department of Pariyaram Medical College.

\section{AGE AND SEX}

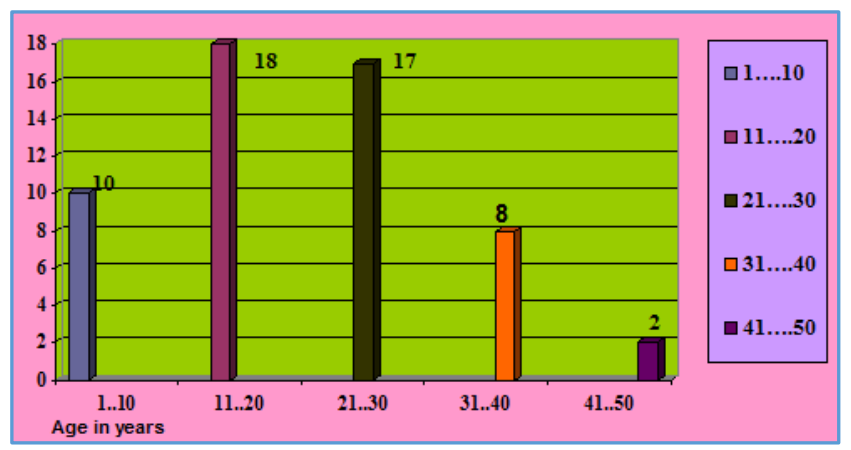

Fig. 1: Age Distribution

The incidence shows [Fig. 1] maximum cases between 1130 years $(63.6 \%)$ and $18.1 \%$ of the patient below 10 years and $3.6 \%$ of patient above 40 years. The youngest patient in this study was 14 months male and the oldest 45 years female.

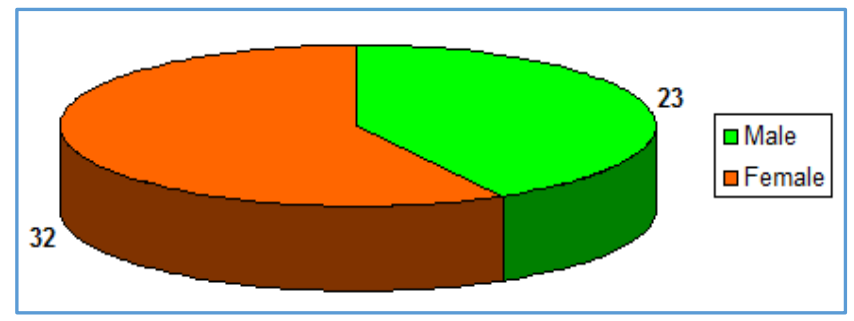

Fig. 2: Sex Distribution

Out of 55 patients, 32 (58.2\%) were female and 23 (41.8\%) were males.

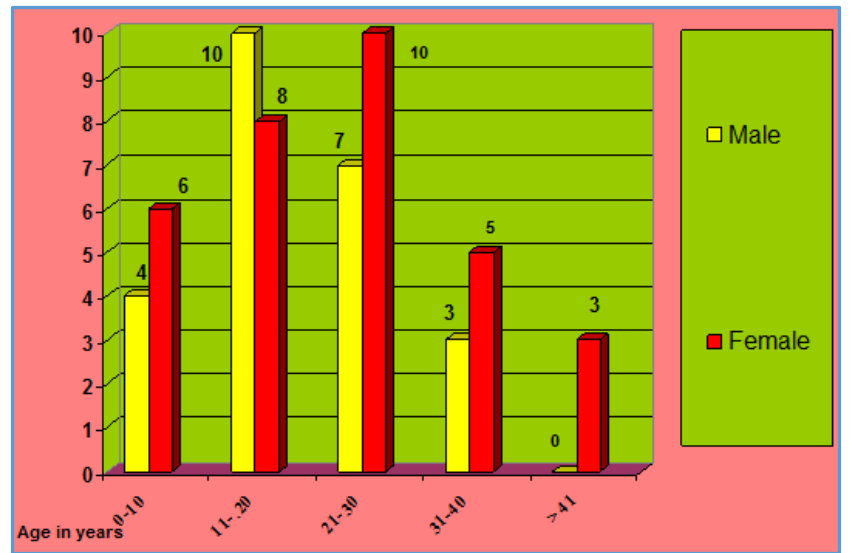

Fig. 3: Age Wise Distribution among Sexes

Data clearly pointing that female were affected more in all age groups except in 11-20 years where males predominate. Maximum incidence in slightly younger males and older females.

\section{Seasonal Variations}

Seasons in Kerala has been marked by a pre-monsoon period/summer [March-May] S/W Monsoon [June-August] N/E Monsoon [September-November] and winter [DecemberFebruary]. ${ }^{1}$

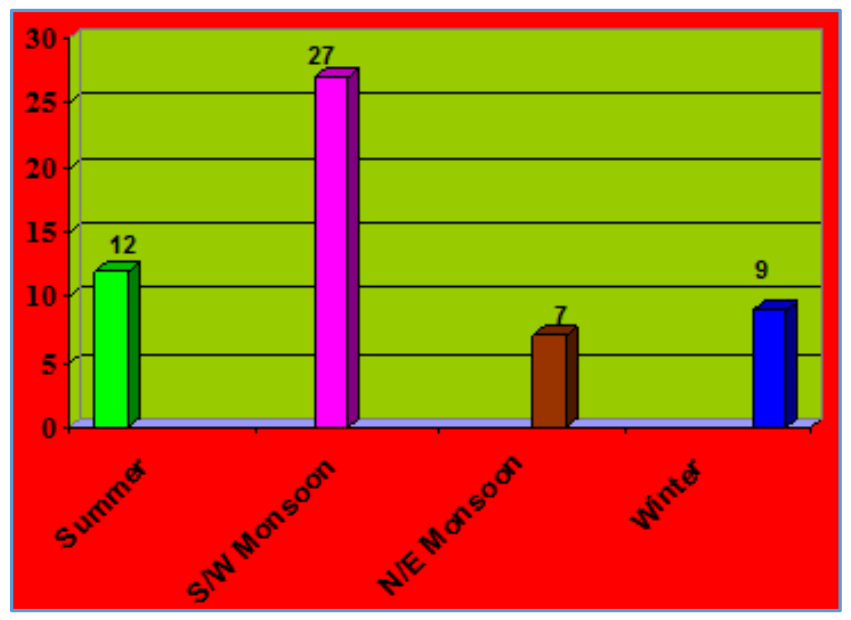

Fig. 4: Seasonal Variations

\section{Seasonal Variations}

In our study, 27 cases (49\%) occurred during south west monsoon in this part of Kerala [June-August]. Twelve cases (21.8\%) during pre-monsoon period [summer] [March-May] and 7 (12.7\%) during North-East monsoon (Sept. - Nov.) and $9(16.3 \%)$ during winter (Dec. - Feb.).

\section{Duration of Illness}

Of the 55 cases, 37 (70.9\%) sought medical attention in the first 2 weeks. By the end of third week, $87.3 \%$ was under medical treatment. 


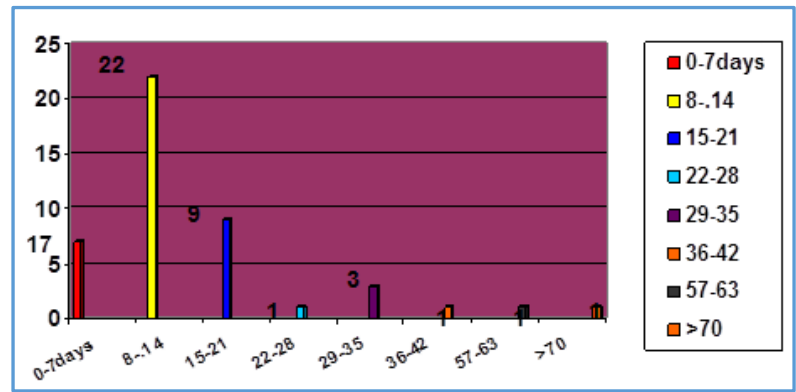

Fig. 5: Duration of Illness

Duration of Illness in Days

\begin{tabular}{|c|c|c|}
\hline Asso. Features & Frequency & Percentage \\
\hline Nil & 46 & 83.6 \\
\hline Fever & 2 & 3.6 \\
\hline Coryza & 4 & 7.3 \\
\hline Fever+coryza & 2 & 3.6 \\
\hline Fever+headache & 1 & 1.8 \\
\hline Total & 55 & 100 \\
\hline
\end{tabular}

\section{Predisposing Factors}

Fever, drugs, atopy 5 cases each (9\%) and new clothes 2 cases $(4 \%)$ observed during the study as the predisposing factors.

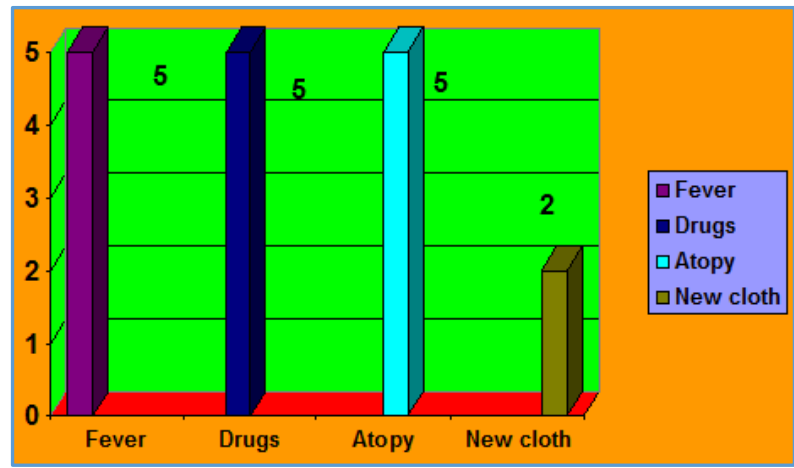

Fig. 6: Predisposing Factors

\section{Pruritus}

Out of 55 cases, 29 (52.7\%) showed moderate-to-severe itching. Itching was absent in $9(16.4 \%)$ cases.

\section{Herald Patch}

In our study, $34(61.8 \%)$ presented with herald patch at the time of examination.

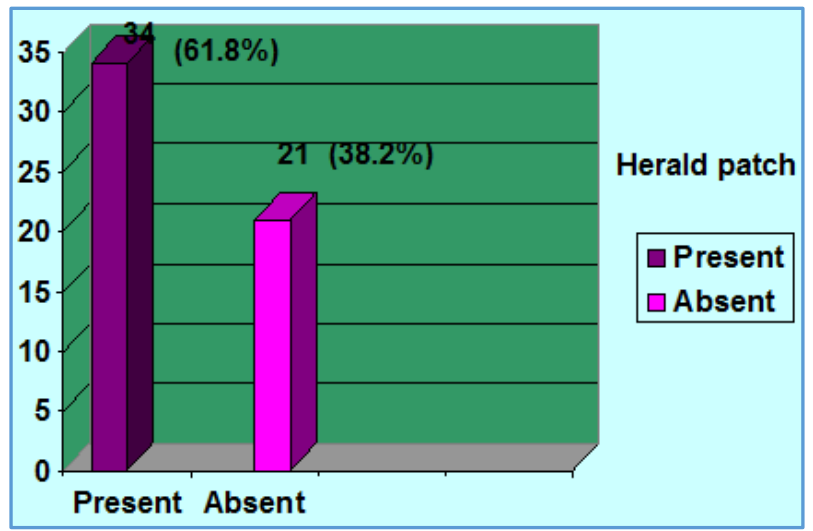

Fig. 7: Herald Patch

\begin{tabular}{|c|c|c|}
\hline Herald Patch Shape & No. of Patients & Percentage \\
\hline Round & 18 & $52.9 \%$ \\
\hline Oval & 16 & $47.1 \%$ \\
\hline \multicolumn{2}{|c|}{ Table 2: Herald Patch Shape } \\
\hline
\end{tabular}

\begin{tabular}{|c|c|c|}
\hline Site & No. of Patients & Percentage \\
\hline Face & 1 & $2.9 \%$ \\
\hline Neck & 1 & $2.9 \%$ \\
\hline Chest & 9 & $26.5 \%$ \\
\hline Back & 5 & $14.7 \%$ \\
\hline Abdomen & 6 & $17.6 \%$ \\
\hline Upper limb & 7 & $20.5 \%$ \\
\hline Lower limb & 5 & $14.7 \%$ \\
\hline \multicolumn{2}{|c|}{ Table 3: Herald Patch-Site } \\
\hline
\end{tabular}

\begin{tabular}{|c|c|c|}
\hline Duration in Days & No. of Cases & Percentage (\%) \\
\hline $0-6$ & 14 & 41.1 \\
\hline $7-13$ & 13 & 38.2 \\
\hline $14-20$ & 3 & 8.8 \\
\hline $21-27$ & 1 & 2.9 \\
\hline $28-34$ & 1 & 2.9 \\
\hline$>35$ & 2 & 5.9 \\
\hline Table 4: Interval between Herald Patch and Sec. Rash \\
\hline
\end{tabular}

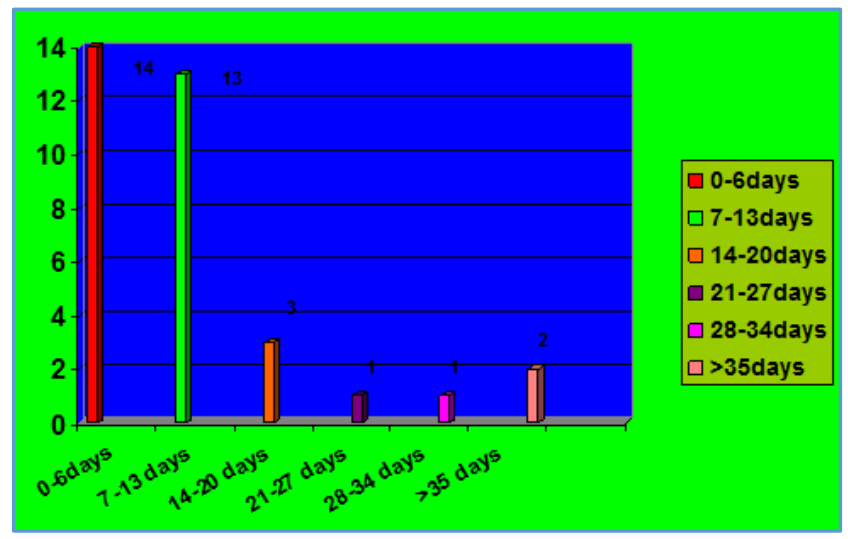

Fig. 8: Sec. Rash Duration

Herald patch was seen in 34 (61.8\%) patients, out of which $9(26.5 \%)$ was on the chest. Herald patch was present in the decreasing frequencies over the upper limb, abdomen, back and lower limb (Table 11). The duration between herald patch and the secondary rash shows that in majority of the cases 27 $(79.3 \%)$ within 2 weeks after the herald patch, that is 14 $(41.7 \%)$ cases within 1 week and $13(38.2 \%)$ cases in the second week.

Type of Secondary Rash

\begin{tabular}{|c|c|c|}
\hline Type of Lesions & No. of Cases & Percentage (\%) \\
\hline Maculopapular & 40 & 72.7 \\
\hline Papular & 12 & 21.8 \\
\hline Combined & 3 & 5.4 \\
\hline \multicolumn{2}{|r|}{ Table 5: Secondary Rash-Type of Lesions } \\
\hline
\end{tabular}

Type of combined lesion
Papulo urticated
Papulo pustular
Papulo plaque

No. of Patients 1

1 1 


\section{Site of Secondary Rash}

Most of the secondary rashes are of maculopapular type 40 (72.7\%), whereas only $12(21.8 \%)$ cases of papular type and 1 each of combined type that is papulo-plaque, papulo-pustular and papulo-urticated.

Majority of the patients had involvement of trunk, 48 (87.5\%) posteriorly and 45 (81.5\%) anteriorly. Arms and thighs in 38 (69\%). Forearm and legs were involved in 25 $(45 \%)$ along with trunk. Face and neck 14 (25.4\%) and axilla and groin 16 (29\%); 2 (3.6\%) cases showed palm and sole involvement.

\section{Secondary Rash Site}

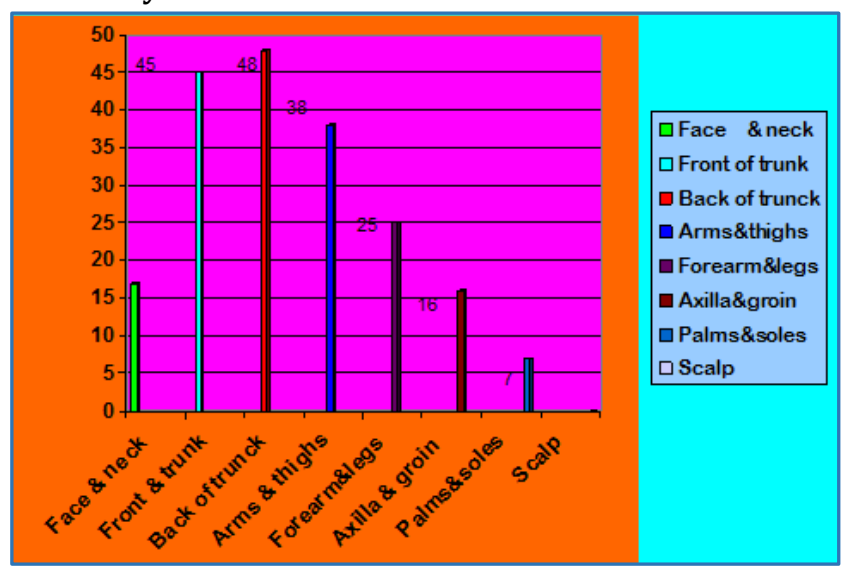

Fig. 9: Secondary Rash Site

\section{DISCUSSION}

\section{Age Incidence}

Most cases of Pityriasis Rosea (PR) occur between ages of 10 and 35 years and are rare in very young and very old. Study by Mandal and Dutta found highest incidence rate in the age group between 11 and 20 with the lowest $2-1 / 2$ years and highest 48 years. ${ }^{2}$

African studies suggest highest number of cases in the age group 15 to 24 years. However, higher percentage of children less than 10 years of age was found to be affected varying from $21-26 \%$ in various African studies. ${ }^{3}$ One year review of PR at National Skin Centre, Singapore, found the peak age group 2029 ranging from 9 months to 82 years. ${ }^{4}$

Present study reveals highest incidence in the age group between 11-30 years (63.6\%). Maximum between 11-20 (34.5\%) years similar to the previous Indian and other studies. The youngest affected was 1 year and 2-month-old male child with congenital heart disease and the oldest 45-year-old female.

\section{Sex Incidence}

Previous large studies in Sweden and England showed equal susceptibility of sexes. ${ }^{5}$ Chuang et al in an epidemiological study spanning 10 years' period at Rochester, Minnesota, found females to be more commonly involved than males with the ratio of 1.5:1.6 In African studies, male-to-female ratio reported is 0.91 (Dogliotti). ${ }^{7}, 0.97$ (Vollum). ${ }^{8}$ and 0.90 (Jacyk). ${ }^{3}$ An Indian study by Mandal and Dutta found a striking predominance among males $77.5 \%$ of males against $22.5 \%$ females. ${ }^{2}$ Study conducted in Singapore showed a male predilection with male-to-female ratio 1.2:1.

In the present study, females outnumber males $(58.2 \%$ females, $41.8 \%$ males). Male-to-female ratio is $0.7: 1$, which is more or less similar to the findings of the African studies. $3,7,8$ and the Rochester study. ${ }^{6}$ However the Indian study by Mandal and Dutta. ${ }^{2}$ showed a male predominance and among the females no case with pregnancy reported.

\section{PREDISPOSING FACTORS \\ Infection}

In the present study, $6.4 \%$ of the patients gave a history of fever, malaise and sore throat prior to the onset of skin eruption. Interval between prodromal symptoms and skin eruptions varied between 5-10 days.

Chung et $\mathrm{al}^{9}$ found a strong association between recent upper respiratory tract infection and subsequent development of PR. Similar findings had been previously reported by Bjornberg and Hellegren. ${ }^{5}$ A multicentre epidemiologic study in primary care settings in Hong Kong. ${ }^{10}$ has found a significant temporal clustering independent of seasonal variation, which might indicate an infectious cause. Tay and Goh.11 in their oneyear review of PR patients found that about a quarter gave a history of prodromal illness shortly before or during the occurrence of rash. Prospective case control study of Chlamydia, Legionella and mycoplasma infections carried out in Hong Kong, China, revealed no symptoms or signs of infections in 13 patients with PR. ${ }^{12}$

Present study revealing a lower percentage of patients with upper respiratory prodrome, also suggests that infectious aetiology in PR need to be substantiated further.

\section{Atopy}

In the present study, personal or family history of atopy was found in 5 patients (9\%). Bjornberg and Hellegren. ${ }^{5}$ had suggested a strong association with atopy. However, this was not confirmed in the Minnesota study. ${ }^{6}$

\section{Drugs}

In the present study, 5 patients (9\%) gave a history of intake of some form of medication prior to the development of PR. The drugs include antibiotics like amoxicillin, cephalosporin ofloxacin and non-steroidal anti-inflammatory drugs. The time interval between the drug intake and onset of skin lesions ranged from 2-3 days to 2 weeks. However, there is no evidence to prove that the drug is the cause for the development of PR.

\section{Garment Contact}

2 cases gave history of wearing new cloth prior to the onset of PR within a period of 3 days. Many old reports associate PR with wearing new unwashed garments or old ones that have been in storage for long periods. ${ }^{13}$ Authors like Niles and Klumpp. ${ }^{14}$ and Epstein. ${ }^{15}$ also supports this view. But this view is not agreed to by Bjornberg and Hellegren. 5 It seems extremely unlikely that wearing new garments has anything to do with the causation of PR, as large majority of the cases lack such a history.

\section{Presence of Pruritus}

In the present study pruritus was present in 46 patients (83.6\%), of which 17 (30.9\%) having mild, 13 (23.6\%) moderate, 16 (29.1\%) having severe pruritus.

Mandal and Dutta. ${ }^{2}$ reported that pruritus of some degree is an almost constant associated feature. Bjornberg. ${ }^{5}$ estimates 
that itching is severe in $25 \%$, moderate in $50 \%$ and absent in $25 \%$.

Sweating aggravates itching and in tropical areas this may contribute to high incidence of itching. Present study is in agreement with the fact that PR is an "itchy" dermatosis and not an asymptomatic problem as mentioned by some.

\section{Herald Patch}

The present study showed Herald patch in 34 (61.8\%) and was absent in 21 (38.2\%).

Prevalence of herald patch varies from series to series from as low as $12 \%$ to as high as $94 \% .^{2-16}$ Multiple herald patches were reported by Niles and Klumpp. ${ }^{14}$ in $5.5 \%$. African studies report 30\% incidence of herald patch. ${ }^{3}$ Mandal and Dutta. ${ }^{2}$ reports a low incidence of $(17.5 \%)$ of herald patch and concluded that herald patch was found to be absent or indistinguishable from the rest of lesions in majority.

In the present study, majority had herald patch over the chest 9 (26.5\%) followed by upper limb 7 (20.5\%), abdomen 6 (17.6\%), back and lower limb 5 each (14.7\%).

The most common site of herald patch reported is over the chest. ${ }^{13}$ and our study also showed the same. Other sites in the order of decreasing frequency are back, neck, abdomen and extremities. ${ }^{1-13}$ Herald patch over the forehead and nose are rarely reported. Studies of PR in Nigerians. ${ }^{3}$ found herald patch commonly on the trunk followed by extremities. Present study showed more involvement of chest, which is similar to other studies. ${ }^{13} \mathrm{~A}$ fairly high incidence was seen on the extremities.

In majority of patients, i.e. 27 (79.3\%) secondary rash appeared within 2 weeks. Three cases in the $3^{\text {rd }}$ week and 4 cases after 3 weeks. Earlier study by Bjornberg and Hellegren. ${ }^{7}$ Antonio Chuh. ${ }^{17}$ also showed similar results.

\section{Morphological Pattern and Distribution}

In the present study, 40 patients (72.7\%) had typical maculopapular lesions with peripheral collarette of scales. Twelve patients $(21.8 \%)$ had papular lesions alone. The youngest and the oldest in the series presented with papular lesions. A combination of various morphological patterns was seen in $3(5.4 \%)$ cases, one each with typical lesion and pustular or plaque variety and third with urticated lesion. Lichenoid, vesiculobullous, purpuric or EM-like lesions were not seen.

Classical presentation of erythematous maculopapular lesions with collarette scaling is reported to occur in $80 \%$ of cases in most series. This high incidence of classical presentation is seen in the present study also.

Urticarial forms are apparently more common in the "highly nervous patient."13 Lesion mimic acute urticaria. In our study, one patient was having urticated papules.

\section{Distribution of Lesions}

In the present study, 48 patients (87.2\%) had lesions on the back and $45(81.8 \%)$ on the front of trunk. In 25 patients (45.4\%), forearm and leg involvement are seen along with lesion of trunk and proximal extremities. Only one patient had inverse pattern with the involvement of face and forearm sparing other areas. Thirty eight patients (69\%) showed involvement of arms and thighs, 14 (25.4\%) cases had face and neck involvement along with trunk. Only 2 cases showed palm and sole involvement; 8 cases had whole body involvement. No scalp or oral lesions were seen in our study.
In majority of case series, $80 \%$ patients follow distinctive and remarkably constant pattern. This is found to be true in the present series as well. Face involvement is seen in $29 \%$, in the study by Jacyk. ${ }^{3}$ and similar observations of greater tendencies to affect face and scalp have been made in other studies from Africa.

Vollum. ${ }^{8}$ reported that PR in Africa differs from Caucasians, in being more severe and extensive and lesions of face, neck, forearm, legs, hands and feet are common. In the study by Lipman and Cohen. ${ }^{18}$ lesion distal to the elbow were seen in $32.5 \%$, distal to the knees in $4.8 \%$ and distal to both knees and elbow in $15.3 \%$. Face involvement was seen in $13.6 \%$ in Cohen's series. However, previous reports by Little. ${ }^{19}$ and Crissey. ${ }^{20}$ revealed rarity of peripheral distribution.

Reports by Mandal and Dutta. ${ }^{2}$ revealed that classical "water-jacket" distribution is infrequently seen in our country. Lesions are found to affect other sites like forehead, neck, back, chest, abdomen, axilla and distal part of forearms and legs.

The high incidence of involvement of back, chest, axilla and groin in the present study is in accordance with that of Cohen. ${ }^{18}$ Mandal and Dutta. ${ }^{2}$

Lesions are found to be bilateral and symmetrical in many series. $^{2}$ This is seen in the present study as well. Aggregation of lesions on the upper part of the trunk and lateral part of the abdominal wall reported by Mandal and Dutta. ${ }^{2}$ was seen in the present study also.

In the present study, it has been observed that lesions of PR can practically appear on any part of the body except scalp and predominant involvement (29\%) of axilla and inguinal area substantiate the reports of Parsons. ${ }^{13}$ and Crissey's. ${ }^{20}$

The shortcoming of the study are small number of study group and only one time observation of the patients in the OPD.

\section{SUMMARY AND CONCLUSIONS}

During the one-year period of study from June 2007 to May 2008, 55 cases of Pityriasis Rosea (PR) attended the Dermatology Outpatient Department of Pariyaram Medical College.

- Higher incidence of PR was found in the age group 11-20 years $(32.7 \%) ; 18.1 \%$ of patients under the age of 10 years and $3.6 \%$ above 40 years. Youngest patient was 14 month-old male and the oldest 45-year-old female.

- Females outnumbered male. Out of 55 patients, 32 (58.2\%) were females and 23 (41.8\%) were males. Maleto-female ratio is $1: 1.39$. When age wise distribution between sexes considered females showed higher frequencies over males in all age groups except in 11-20 years, where male predominate. Peak incidence is slightly earlier in males than females.

- Majority of cases occurred during the southwest monsoon period (June-August) 27 (49\%) and premonsoon period (March-May) 12 cases.

- Among various predisposing factors personal and family history of atopy and drugs (Analgesics, Antibiotics) predominate. Total $10(18 \%)$ patients had such history.

- Majority of patients had pruritus $83.6 \%$. Nearly $52 \%$ showed moderate-to-severe episodes.

- Herald patch was present in $61.8 \%$ of patients. Multiple herald patches were not observed. Herald patches observed over chest, abdomen, upper limb, back and lower limb in the decreasing order. 
- $\quad$ Most cases 27 (79.3\%) secondary rashes appeared within 2 weeks after the herald patch.

- Maculopapular rashes predominate in $72.7 \%$ of cases. Few cases $21.8 \%$ showed papular variety. One case each of urticated, pustular and plaque variety observed.

- Secondary rashes showed preponderance over the trunk, mostly posterior than anterior $87.5 \%$ and $81.5 \%$ respectively. Face and neck along with trunk was seen in $25.4 \%$ of cases. One inverse PR and 2 cases with palm and sole involvement was also observed. Scalp and oral lesions are not met with.

- Pityriasis rosea shows a definite seasonal variation centering around the onset of south west monsoon. Young adults (11-30 yrs.) are more prone for the disease, and a personal and family history of atopy has a predisposing role.

\section{REFERENCES}

1. Ananthakrishnan R, Parthasarathy B, Pathan JM. Meterology of Kerala. Contributions to Marine sciences 1979:60-125.

2. Mandal SB, Dutta AK. A clinical study of pityriasis rosea. Ind J Dermatol 1972;17(4):100-5.

3. Jacyk WK. Pityriasis in Nigerians. Int J Dermatol 1980;19(7):397-9.

4. Klauder JV. Pityriasis rosea with particular reference to its unusual manifestations. JAMA 1924;82(3):178-83.

5. Bjornberg A, Hellegren I. Pityriasis rosea: a statistical, clinical and laboratory investigation of 826 patients and matched healthy controls. Acta Derm Venereol 1962;42(50):1-68.

6. Chuang T, Ilstrup DM, Perry HO, et al. Pityriasis rosea in Rochester, Minnesota, 1969 to 1978: a 10 year epidemiologic study. J Am Acad Dermatol 1982;7(1): 80-9.

7. Dogliotti M. Survey of skin disorders in the urban black population of South Africa. Br J Dermatol 1975;93(3):259-70.
8. Vollum DT. Pityriasis rosea in the Africans. Trans St John's Hosp Dermatol Soc 1973;59(2):269-71.

9. Chaung T, Perry HO, Ilstrup DM. Recent upper respiratory tract infection and pityriasis rosea- a case control study of 249 matched pairs. Br J Dermatol 1981;108(5):587-91.

10. Chuh AA, Lee A, Molinari N. Case clustering in pityriasis rosea: a multicentre epidemiologic study in primary care settings in Hong Kong. Arch Dermatol 2003;139(4):48993.

11. Tay YK, Goh CL. One year review of pityriasis rosea at the national skin center, Singapore. Ann Acad Med Singapore 1999;28(6):829-31.

12. Chuh AA, Chan HHL. Prospective case control study of chlamydia, legionella and mucoplasma infections in patients with pityriasis rosea. Eur J Dermatol 2002;12(2):170-3.

13. Parsons JM. Pityriasis rosea update: 1986. J Am Acad dermatol 1986;15(2 Pt 1):159-67.

14. Niles HD, Klumpp MM. Pityriasis rosea-review of literature and report of 219 cases. Arch Derm syph 1960;41:265.

15. Epstein S. Aetiology of pityriasis rosea: role of new garments and underwear in its causation. Urol Rev 1943;47:641-2.

16. Percival GH. Pityriasis rosea. Br J Dermatol 1932;44:24153.

17. Chuh A, Lee A, Zawar V, et al. Pityriasis rosea- an update. Indian J Dermatol Venereol Leprol 2005;71(5):311-5.

18. Cohen EL. Pityriasis rosea. $\mathrm{Br} \mathrm{J}$ Dermatol 1967;79(10):533-7.

19. Little EGG. Discussion on pityriasis rosea. Proc Roy Soc Med 1914;7:121.

20. Crissey JT. Pityriasis rosea. Paed Clinics North America 1956;3:801-9. 